\section{Pacific Northwest}

National Laboratory

Operated by Battelle for the

U.5. Department of Energy

\section{Preliminary F easibility Study of U sing Solid-State $\mathbf{N}$ uclear Magnetic Resonance S pectroscopy to Characterize $\mathrm{H}$ anford Tank Waste Solids}

\author{
H. M. Cho \\ G. J. Lumetta
}

October 2001

Prepared for the U.S. D epartment of Energy under Contract DE-AC06-76RL01830

This work is funded by the O ffice of Science and Technology, within the Department of Energy's O ffice of environmental Management, under the Tanks Focus Area. 


\title{
Preliminary Feasibility Study of Using Solid-State Nuclear Magnetic Resonance Spectroscopy to Characterize Hanford TankWaste Solids
}

\author{
H. M. Cho \\ G. J. Lumetta
}

October 2001

Prepared for the U.S. Department of Energy under Contract DE-AC06-76RL01830

This work is funded by the Office of Science and Technology, within the Department of Energy's Office of Environmental Management, under the Tanks Focus Area.

Pacific Northwest National Laboratory

Richland, Washington 99352 



\section{Summary}

This report describes experiments performed in FY 2001 to examine the feasibility of using nuclear magnetic resonance (NMR) spectroscopy to characterize Hanford tank sludge solids. The results demonstrate the potential utility of magic-angle spinning solid-state NMR spectroscopy for this purpose. We have shown that ${ }^{27} \mathrm{Al}$ NMR signals can be easily detected in samples simulating the compositions of Hanford tank sludge solids. Different Al-containing species can be distinguished on the basis of a number of characteristics, including resonance frequency, lineshape, and response to excitation pulse length of the ${ }^{27} \mathrm{Al}$ NMR signal. This work also indicates that ${ }^{23} \mathrm{Na}$ NMR can likely be used to identify specific Na-containing phases present in tank wastes. It is expected that other NMR-active nuclides can be probed for information about specific phases present in tank-waste solids. 



\section{Glossary}

$\begin{array}{ll}\text { AA } & \text { Atomic Adsorption } \\ \text { ESW } & \text { enhanced sludge washing } \\ \text { HLW } & \text { high-level waste } \\ \text { ICP } & \begin{array}{l}\text { inductively coupled plasma } \\ \text { immobilized high-level waste }\end{array} \\ \text { LLW } & \text { low-level waste } \\ \text { MAS } & \text { magic-angle spinning } \\ \text { NMR } & \text { nuclear magnetic resonance } \\ \text { PLM } & \text { polarized light microscopy } \\ \text { PNNL } & \text { Pacific Northwest National Laboratory } \\ \text { TFA } & \text { Tanks Focus Area } \\ \text { WTP } & \text { Waste Treatment Plant } \\ \text { XRD } & \text { X-ray diffraction }\end{array}$





\section{Acknowledgments}

This work was funded by the U.S. Department of Energy Office of Science and Technology through the Tanks Focus Area (TFA). The authors thank Phil McGinnis of the TFA for supporting this work. The authors also acknowledge Ted Pietrok and Marcus Glasper in the U.S. Department of Energy Richland Operations Office.

The authors gratefully acknowledge W. C. Cosby and B. M. Rapko for reviewing this document. The authors also thank C. L. Blair, W. F. Bonner, P. A. Meyer, and J. Jao for their project-management support.

Pacific Northwest National Laboratory is operated by Battelle for the U.S. Department of Energy under Contract DE-AC06-76RL01830. 



\section{Contents}

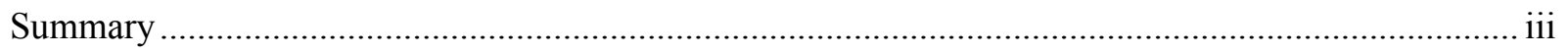

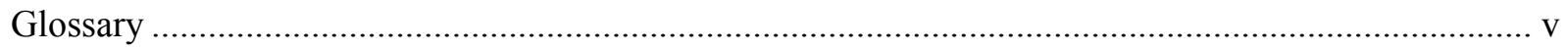

Acknowledgments............................................................................................................... vii

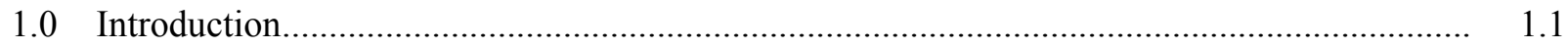

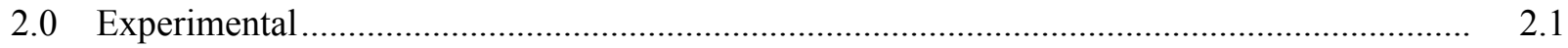

2.1 Preparation of Iron-Doped Aluminum Oxy/Hydroxide............................................. 2.1

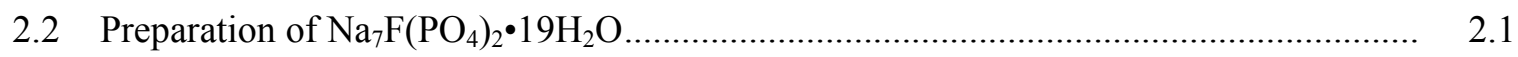

2.3 Preparation of Tank S-101 Sludge Simulant ............................................................ 2.1

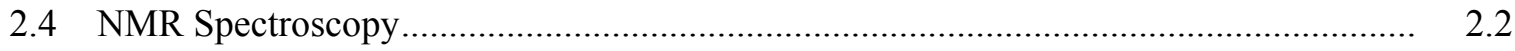

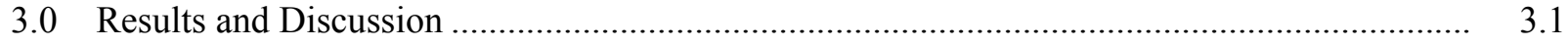

3.1 Aluminum-27 NMR of Iron-Doped Aluminum Oxy/Hydroxide ................................... 3.1

3.2 Sodium-23 NMR Spectroscopy of Sludge Simulants and Salts .................................. 3.2

3.3 Conclusions and Recommendations ..................................................................... 3.5

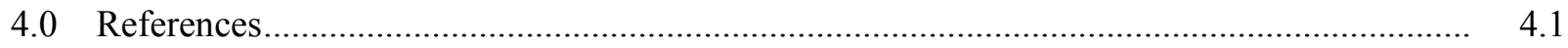

\section{Figures}

1.1. Proposed Methodology For Optimizing the ESW Process .................................................... 1.4

3.1. Proton-Decoupled MAS NMR Echo Spectra of S-23 Gibbsite (a, b), S-11 Gibbsite (c, d), HiQ-10 Boehmite (e, f), Tank S-101 Sludge Simulant (prepared by Lynntech, Inc.) (g, h), and A-400 Nepheline $(i, j)$

3.2. Proton-Decoupled MAS NMR Spectra of Aluminates with Varying Iron Concentrations........ 3.4

3.3. Proton-Decoupled ${ }^{23} \mathrm{Na}$ MAS NMR Echo Spectra of Tank S-101 Sludge Simulant (top) and $\mathrm{Na}_{7} \mathrm{~F}\left(\mathrm{PO}_{4}\right) 2 \cdot{ }^{19} \mathrm{H}_{2} \mathrm{O}$ (bottom)

\section{Tables}

2.1. Preparation of Iron-Doped Aluminum Oxy/Hydroxide Samples .......................................... 2.1

2.2. Compounds Used in Preparing the S-101 Simulant ........................................................ 2.2 



\subsection{Introduction}

Since 1990, the primary mission at the U.S. Department of Energy's Hanford Site has changed from producing plutonium to restoring the environment. Large volumes of high-level radioactive wastes (HLW), generated during past Pu production and other operations, are stored in underground tanks onsite. The current plan for remediating the Hanford tank farms consists of waste retrieval, pretreatment, treatment (immobilization), and disposal. The tank wastes will be partitioned into high-level and lowlevel fractions. The low-level waste (LLW) will be processed to remove ${ }^{137} \mathrm{Cs}$ and ${ }^{99} \mathrm{Tc}$ (and ${ }^{90} \mathrm{Sr}$ and transuranic elements in selected cases), and then it will be immobilized in a glass matrix and disposed of by shallow burial onsite. The HLW will be immobilized in a borosilicate glass matrix; the resulting glass canisters will then be disposed of in a geologic repository (DOE/ORP 2001). Because of the expected high cost of HLW vitrification and geologic disposal, pretreatment processes will be implemented to reduce the volume of immobilized high-level waste (IHLW).

Dilute hydroxide washing is the minimum pretreatment that would be performed on Hanford tank sludges. In this method, the sludge is mixed with dilute $(0.1 \mathrm{M}$ or less) $\mathrm{NaOH}$, and then some sort of solid/liquid separation is performed. This is meant to remove water-soluble sludge components (mainly sodium salts) from the HLW stream. Dilute hydroxide is used rather than water to maintain the ionic strength high enough that colloidal suspensions are avoided.

Caustic leaching (sometimes referred to as enhanced sludge washing or ESW) represents the baseline method for pretreating Hanford tank sludges. Caustic leaching is expected to remove a large fraction of the $\mathrm{Al}$, which is present in large quantities in Hanford tank sludges. The Al will be removed by converting aluminum oxides/hydroxides to sodium aluminate. For example, boehmite and gibbsite are dissolved according to the following equations (Weber 1982).

$$
\begin{gathered}
\mathrm{AlOOH}(\mathrm{s})+\mathrm{NaOH}(\mathrm{aq}) \rightarrow \mathrm{NaAlO}_{2}(\mathrm{aq})+\mathrm{H}_{2} \mathrm{O} \\
\mathrm{Al}(\mathrm{OH})_{3}(\mathrm{~s})+\mathrm{NaOH}(\mathrm{aq}) \rightarrow \mathrm{NaAlO}_{2}(\mathrm{aq})+2 \mathrm{H}_{2} \mathrm{O}
\end{gathered}
$$

A significant portion of the $\mathrm{P}$ is also expected to be removed from the sludge by metathesis of waterinsoluble metal phosphates to insoluble hydroxides and soluble $\mathrm{Na}_{3} \mathrm{PO}_{4}$. An example of this is shown for iron(III) phosphate in the following equation.

$$
\mathrm{FePO}_{4}(\mathrm{~s})+3 \mathrm{NaOH}(\mathrm{aq}) \rightarrow \mathrm{Fe}(\mathrm{OH})_{3}(\mathrm{~s})+\mathrm{Na}_{3} \mathrm{PO}_{4}(\mathrm{aq})
$$

Similar metathesis reactions can also occur for insoluble sulfate salts, allowing the removal of sulfate from the HLW stream.

Based on its known amphoteric behavior (Rai, Sass, and Moore 1987), $\mathrm{Cr}$ (III) was expected to be removed by caustic leaching according to the following equation:

$$
\mathrm{Cr}(\mathrm{OH})_{3}(\mathrm{~s})+\mathrm{NaOH}(\mathrm{aq}) \rightarrow \mathrm{Na}\left[\mathrm{Cr}(\mathrm{OH})_{4}\right](\mathrm{aq})
$$


However, studies conducted at the Pacific Northwest National Laboratory (PNNL) have suggested that the behavior of $\mathrm{Cr}$ in the caustic leaching process is more complex (Lumetta et al. 1997).

Results of previous studies of the baseline Hanford sludge-washing and caustic-leaching process have been reported (Lumetta and Rapko 1994; Rapko et al. 1995, Lumetta et al. 1996a and b, 1997, and 1998; Temer and Villarreal 1995, 1996, and 1997). Although considerable ESW data are available, parametric tests for process optimization have been limited to six tanks (B-101, BX-110, BX-112, C-102, S-101, and S-110). Also, the data generated to date are for sludges from specific tanks, and how well the samples examined represent the entire tank contents is arguable. It is expected that some blending of different tank sludges will be done to help reduce the IHLW volume. Thus, what is actually processed in the Hanford Waste Treatment Plant (WTP) will be different than what has been previously tested. Extrapolation of the existing results to the batches of sludge actually processed is risky.

The process must be optimized for the WTP to operate in the most efficient manner. One option for optimizing the sludge pretreatment process for a given batch of sludge is empirical in nature. Following this approach, the waste sample would be subjected to a series of parametric studies. Parameters that would be varied include $\mathrm{NaOH}$ concentration, temperature, solution-to-solids ratio, and leaching duration. Parametric sludge leaching tests of this type have been performed on six Hanford tank sludges, providing useful information regarding the choice of processing conditions (Lumetta et al. 1998 and 2001). These parametric studies have also highlighted the desirability of different processing conditions for different sludges. This approach, however, has a number of disadvantages, including:

- Hundreds of grams of sample required

- Extensive and expensive laboratory testing needed

- Completion of parametric testing required before processing can proceed

- Mixed laboratory wastes generated

- Laboratory personnel exposed to radiation.

An alternative approach is outlined in Figure 1.1. Under this approach, the solid phases present in the sludge are identified and quantified. Based on this characterization and the established process goals, the target removal levels for the key components (e.g., Al, Cr, P) can be established. Using thermodynamic and kinetic models, the optimal process conditions required to meet the processing goals can be determined. Then the ESW process can proceed. For example, two Al-containing compounds that have been previously identified to be present in Hanford sludges are gibbsite $\left[\mathrm{Al}(\mathrm{OH})_{3}\right]$ and boehmite $[\mathrm{AlO}(\mathrm{OH})]$. These two compounds have dramatically different solubilities and dissolution kinetics in aqueous $\mathrm{NaOH}$. If the $\mathrm{Al}$ in a given batch of sludge is found to be primarily gibbsite, then the process goals could likely be met with relatively low $\mathrm{NaOH}$ (e.g., $1 \mathrm{M}$ ) and temperature (e.g., $60^{\circ} \mathrm{C}$ ). However, if the $\mathrm{Al}$ is present mostly as boehmite, more severe conditions (e.g., $3 \mathrm{M} \mathrm{NaOH}, 85^{\circ} \mathrm{C}$, for several days) would likely be needed to achieve the process goals. Properly designed thermodynamic and kinetic models could be used to select the process conditions needed to remove the required amount of Al while minimizing operating costs. This approach has the following advantages:

- Very little sample required

- Extensive and expensive laboratory testing avoided 
- Processing delay kept to a minimum because of relatively rapid turn-around

- Minimal mixed laboratory wastes generated

- Radiological exposure greatly reduced.

For this approach to be successful, accurate thermodynamic and kinetic models are needed. Several years ago, MacLean et al. investigated applying the Environmental Simulation Program (ESP) (OLI Systems, Inc.) to modeling the washing and leaching of Hanford tank sludges (MacLean 1997; Barton et al. 1995; Meng et al. 1994). More recently, the TFA has funded an effort at the Mississippi State University to expand work they have done on ESP modeling of saltcake dissolution (Toghiani et al. 1998 and 2000) to the modeling of sludge leaching. The TFA is also funding work at PNNL to improve the ESP model by introducing Pitzer parameters for determining solution activities. Henshaw et al. have developed a kinetic model for gibbsite dissolution (Henshaw et al. 1998; Morgan and Henshaw 1999), but a more comprehensive consideration of dissolution kinetics for other sludge components is still required.

The third critical capability for this approach to be successful is the ability to identify and quantify the important chemical phases present in the sludge solids. We have begun to explore the application of solid-state nuclear magnetic resonance (NMR) spectroscopy for this purpose. Most elements have isotopes that absorb and emit radiofrequency energy in well-defined bands when placed in high magnetic fields. Nuclear magnetic resonance spectroscopy is based on the measurement of these energies. The energy of the emission is highly resolved and very sensitive to the local environment of the atom, and thus measurements of NMR frequencies provide a discriminating method for identifying the molecule or lattice occupied by an atom.

Aluminum-27 and ${ }^{23} \mathrm{Na}$ are isotopes with favorable properties for NMR measurements, and numerous references have been compiled to interpret their NMR spectra (Laszlo 1983; Akitt 1987; Grant and Harris 1996). For ${ }^{27} \mathrm{Al}$ and ${ }^{23} \mathrm{Na}$, the most important determinants of the NMR frequencies are the chemical shift and quadrupolar interactions, and, to a lesser extent, internuclear $J$ and dipolar couplings. There is ample previous work on inorganic solids to suppose that NMR measurements of these quantities for ${ }^{27} \mathrm{Al}$ and ${ }^{23} \mathrm{Na}$ will have useful applications in the analysis of sludges, especially in the identification and quantification of metal oxide species. The NMR signals of Al atoms in four-fold coordinated sites, for example, appear in a different frequency band in the ${ }^{27} \mathrm{Al}$ spectrum than atoms in a six-fold site, due to the difference in chemical shifts. In contrast to diffraction methods, NMR techniques are effective even for amorphous, glassy, non-crystalline, or mixed-phase solids, and for slurries, pastes, or liquids.

The integrated intensity of the NMR signal is proportional to the concentration of the observed isotope, and thus NMR may also be used to determine the relative concentrations of the resolved species in an NMR spectrum. Through comparison with a standard of known concentration, absolute concentrations may also be measured.

This report describes experiments performed in FY 2001 to test the feasibility of using NMR spectroscopy to characterize Hanford tank sludge solids. The work focused on measuring ${ }^{27} \mathrm{Al}$ NMR spectra of aluminum oxy/hydroxides containing varying amounts of iron(III). This was done to assess the effects of the paramagnetic iron(III) on the capability to measure the ${ }^{27} \mathrm{Al}$ NMR signal. 


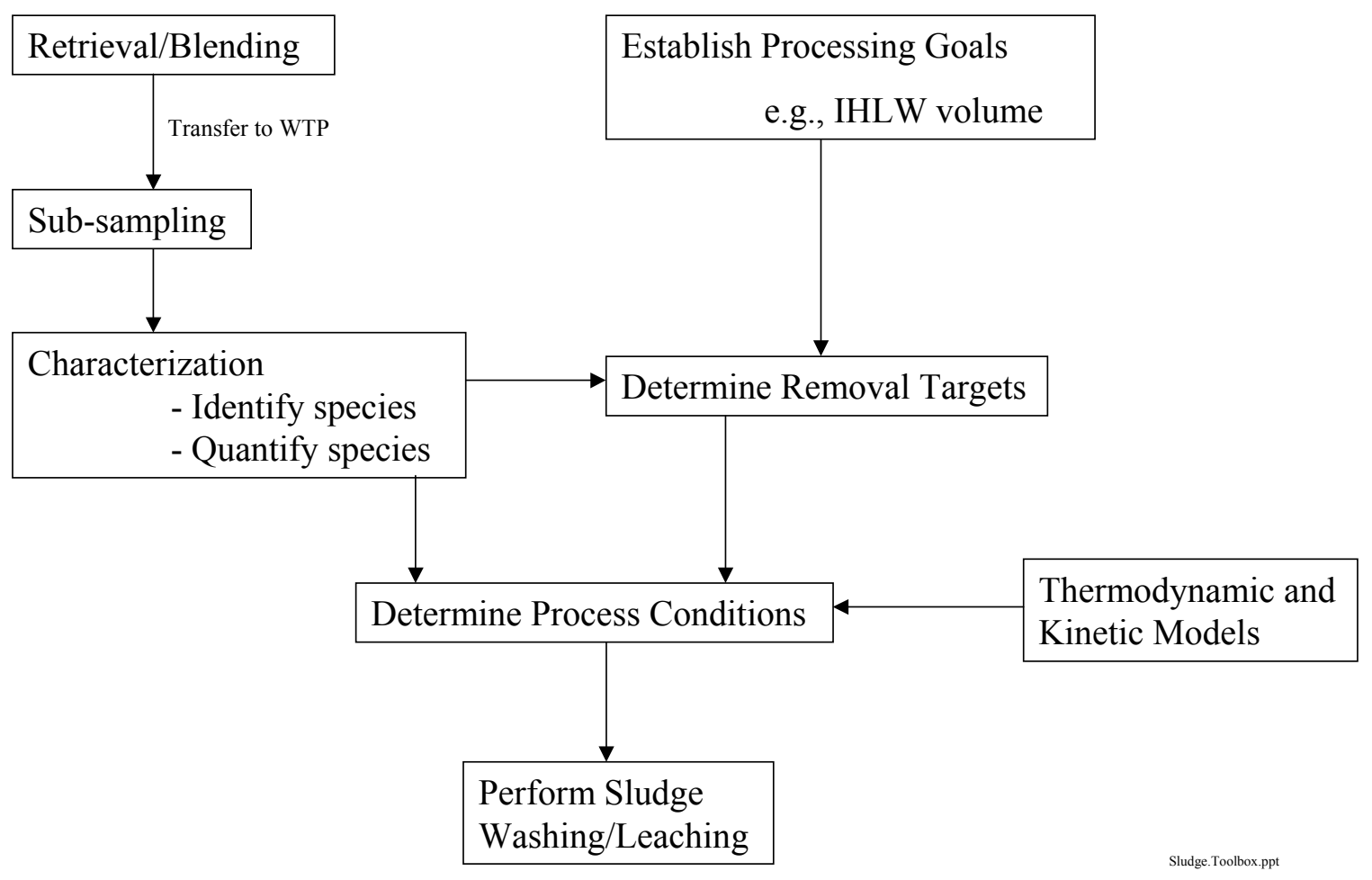

Figure 1.1. Proposed Methodology For Optimizing the ESW Process 


\subsection{Experimental}

\subsection{Preparation of Iron-Doped Aluminum Oxy/Hydroxide}

Ferric nitrate solution $(1 \mathrm{M})$ was added to $20-\mathrm{mL}$ portions of $1.6 \mathrm{M} \mathrm{Al}\left(\mathrm{NO}_{3}\right)_{3}$ solution in the volumes indicated in Table 2.1. The resulting $\mathrm{Al}(\mathrm{III}) / \mathrm{Fe}(\mathrm{III})$ solution was added to $100 \mathrm{~mL}$ of $1 \mathrm{M} \mathrm{NaOH}$ while stirring. The $\mathrm{pH}$ was adjusted to a value between 10 and 11 with $1 \mathrm{M} \mathrm{NaOH}$, as required. The mixture was then heated to boiling for $1 \mathrm{~h}$, replenishing with deionized water as needed to maintain the original volume. After cooling to ambient temperature, the mixture was transferred to centrifuge tubes and centrifuged, and then the liquid was decanted. The solids were washed with several portions of deionized water and then dried under a heat lamp. Each sample was analyzed for Al and Fe content by Desert Analytics Laboratory (Tucson, Arizona) using atomic adsorption/inductively coupled plasma (AA/ICP) spectroscopy.

Table 2.1. Preparation of Iron-Doped Aluminum Oxy/Hydroxide Samples

\begin{tabular}{||c|c|c|c||}
\cline { 2 - 4 } \multicolumn{1}{c|}{} & \multicolumn{2}{c|}{ Analyzed Conc., wt\% } \\
\hline Target Fe Conc., wt\% & Vol. 1 M Fe(NO $\left.\mathbf{~}_{3}\right)_{3}, \mathbf{~ m L}$ & Al & Fe \\
\hline 0 & 0 & 31.28 & 0.02 \\
\hline 1 & 0.46 & 31.10 & 0.99 \\
\hline 2.5 & 1.17 & 30.45 & 2.56 \\
\hline 5 & 2.47 & 25.78 & 4.46 \\
\hline 7.5 & 3.91 & 22.26 & 5.83 \\
\hline 10 & 5.53 & 20.77 & 8.43 \\
\hline
\end{tabular}

\subsection{Preparation of $\mathrm{Na}_{7} \mathrm{~F}\left(\mathrm{PO}_{4}\right)_{2} \cdot 19 \mathrm{H}_{2} \mathrm{O}$}

Aqueous $\mathrm{NaF}(0.3 \mathrm{M}, 50 \mathrm{~mL})$ was mixed with aqueous $\mathrm{Na}_{3} \mathrm{PO}_{4}(0.6 \mathrm{M}, 50 \mathrm{~mL})$, and $\mathrm{NaOH}(3.97 \mathrm{~g})$ was added. A white solid precipitated upon standing. The product was filtered, washed with a small amount of cold deionized water, and air-dried. Polarized light microscopy (PLM) confirmed that the product was $\mathrm{Na}_{7} \mathrm{~F}\left(\mathrm{PO}_{4}\right)_{2} \bullet 19 \mathrm{H}_{2} \mathrm{O}$, but there was a small amount (estimated to be 1 to $2 \%$ ) of an unidentified impurity. ${ }^{\text {(a) }}$

\subsection{Preparation of Tank S-101 Sludge Simulant ${ }^{(b)}$}

Soluble salts of the desired components (Table 2.2$)$ were dissolved in deionized water $(\sim 3.5 \mathrm{~L})$, and the $\mathrm{pH}$ was adjusted to between 9 and 10 with $50 \% \mathrm{NaOH}$ to precipitate the corresponding hydroxides. Boehmite was also added to the simulant because this had been previously identified to be present in the S-101 sludge (Lumetta et al. 1997). The resulting mixture was heated at $100^{\circ} \mathrm{C}$ for $48 \mathrm{~h}$, centrifuged, and

(a) Dan Herting at the Hanford 222-S Laboratory performed the PLM analysis.

(b) J. Kim et al. at Lynntech, Inc. (College Station, Texas) prepared the S-101 sludge simulant under a separate project. 
washed with $0.01 \mathrm{M} \mathrm{NaNO}_{3}$ that had been adjusted to $\mathrm{pH} 9$ with $\mathrm{NaOH}$. The washed solids were stored in a sealed plastic bottle until required for use.

Table 2.2. Compounds Used in Preparing the S-101 Simulant

\begin{tabular}{||c|l|c||}
\hline Component & \multicolumn{1}{|c|}{ Source } & Amount Added, g \\
\hline $\mathrm{Al}$ & $\mathrm{Al}\left(\mathrm{NO}_{3}\right)_{3} \cdot 9 \mathrm{H}_{2} \mathrm{O}$ & 951 \\
\hline $\mathrm{Al}$ & $\mathrm{Boehmite}, \mathrm{AlOOH}$ & 152 \\
\hline $\mathrm{Ca}$ & $\mathrm{Ca}\left(\mathrm{NO}_{3}\right)_{2} \cdot 4 \mathrm{H}_{2} \mathrm{O}$ & 5.12 \\
\hline $\mathrm{Cr}$ & $\mathrm{Cr}\left(\mathrm{NO}_{3}\right)_{3} \cdot 9 \mathrm{H}_{2} \mathrm{O}$ & 32.3 \\
\hline $\mathrm{Fe}$ & $\mathrm{Fe}\left(\mathrm{NO}_{3}\right)_{3} \cdot 9 \mathrm{H}_{2} \mathrm{O}$ & 15.9 \\
\hline $\mathrm{Mn}$ & $\mathrm{Mn}\left(\mathrm{NO}_{3}\right)_{3}, 50 \%$ Solution & 18 \\
\hline $\mathrm{Na}$ & $\mathrm{NaNO}_{3}$ & 22.5 \\
\hline $\mathrm{P}$ & $\mathrm{Na}_{3}\left(\mathrm{PO}_{4}\right) \cdot 12 \mathrm{H}_{2} \mathrm{O}$ & 1.22 \\
\hline
\end{tabular}

\subsection{NMR Spectroscopy}

Nuclear magnetic resonance measurements were performed at ambient temperature in a Chemagnetics CMX Infinity spectrometer system (Palo Alto) equipped with a 7.05 Tesla superconducting magnet (Oxford Instruments, Oxford, England). The NMR frequencies for ${ }^{27} \mathrm{Al}$ and ${ }^{23} \mathrm{Na}$ in this magnet were 78.17 MHz and 79.35 MHz, respectively. A Chemagnetics 5-mm HXY magic-angle-spinning (MAS) probe was used for all experiments. The calibrated $90^{\circ}$ pulse width for the middle channel of this probe was approximately $3.5 \mu \mathrm{s}$, corresponding to a $\mathrm{B}_{1}$ field amplitude of $71.4 \mathrm{kHz}$, or over $900 \mathrm{ppm}$ for both ${ }^{27} \mathrm{Al}$ and ${ }^{23} \mathrm{Na}$. All compounds were crushed to a fine powder before loading in the sample holders. Sample masses ranged from 130 to $210 \mathrm{mg}$.

In keeping with standard practice, the ${ }^{27} \mathrm{Al}$ chemical shifts are referenced with respect to the resonance of a $1 \mathrm{M} \mathrm{Al}\left(\mathrm{H}_{2} \mathrm{O}\right)_{6}{ }^{3+}$ solution, and ${ }^{23} \mathrm{Na}$ chemical shifts are referenced with respect to the resonance of a $0.5 \mathrm{M} \mathrm{NaCl}(\mathrm{aq})$ solution. All spectra reported here were acquired with ${ }^{1} \mathrm{H}$ decoupling and two-pulse echo detection. 


\subsection{Results and Discussion}

\subsection{Aluminum-27 NMR of Iron-Doped Aluminum Oxy/Hydroxide}

Figure 3.1 displays the ${ }^{27} \mathrm{Al}$ MAS NMR spectra of a series of standard compounds. These spectra illustrate that ${ }^{27} \mathrm{Al}$ NMR spectra can be obtained rapidly $(<1 \mathrm{~h})$, non-destructively, and with good sensitivity on relatively small amounts of material. In addition, the easily identified features of each spectrum demonstrate that the phases expected to dominate the aluminous fraction of sludge solids can be readily differentiated and quantified on the basis of NMR measurements.

Gibbsite $\left[\gamma-\mathrm{Al}(\mathrm{OH})_{3}\right]$, boehmite $(\gamma-\mathrm{AlOOH})$, and nepheline $\left(\mathrm{NaAlSiO}_{4}\right)$ spectra have been previously investigated by NMR spectroscopy, and the spectra in Figure 3.1 agree with data reported in the literature (Woessner 1989; Slade et al. 1991a, 1991b). The main determinant of the ${ }^{27} \mathrm{Al}$ line position in these spectra is the coordination number of the metal. In gibbsite and boehmite, the aluminum atoms are coordinated to six oxygen atoms, while in nepheline, the aluminum atoms are fourfold coordinated with oxygen. This is revealed in the positions of the ${ }^{27} \mathrm{Al}$ NMR resonances, which is centered around $0 \mathrm{ppm}$ for the gibbsite and boehmite spectra and around $60 \mathrm{ppm}$ for the nepheline spectrum, in accordance with previous studies of model aluminum oxides.

Although the ${ }^{27} \mathrm{Al}$ line positions of gibbsite and boehmite overlap, comparison of the spectra indicates that differentiation of sixfold-coordinated sites is nevertheless possible on the basis of other spectral features, including lineshape and spinning sideband patterns. In particular, spectra of gibbsite are characterized by a slight shoulder to the right of the main peak that is absent in spectra of boehmite. The extensive sideband ranges of aluminum oxide and hydroxides seen in the right series of spectra have been attributed to the large anisotropic quadrupolar couplings at the metal sites and the wide distribution of electronic environments that results from the lack of long-range order and crystallinity in these phases. Boehmite typically displays a narrower sideband range than gibbsite and nepheline, as observed in the spectra of the HiQ-10 boehmite. This characteristic is evident in the spectrum of the Lynntech Tank S-101 sludge simulant (Figure 3.1g,h), which is dominated by features of the boehmite spectra, but exhibits a weak, extended sideband pattern, indicating the presence of a small fraction of gibbsite. X-ray diffraction (XRD) analysis has confirmed the assignment of most of the aluminum to a boehmite phase in these simulated sludge solids.

A preliminary study to determine the effects of Fe on the NMR measurements has been initiated. Iron is a paramagnetic metal in the +2 and +3 oxidation states, and its presence in a sample can have undesirable consequences for NMR experiments at concentrations as low as $0.1 \mathrm{wt} \%$. In particular, the resolution can be degraded, and for nuclei within $10 \AA$ of an iron center, NMR lines can be unobservable due to severe line-broadening. While initial results confirm that resolution is indeed considerably reduced, the magnitude and relaxation times of the ${ }^{27} \mathrm{Al}$ signal from iron-containing samples (Figure 3.2) suggest that nearly all of the aluminum can be detected in samples with iron levels typically found in Hanford tank sludge solids. In reaching this conclusion, we make use of the property of NMR spectra, discussed in the Introduction, that the integrated intensity of the ${ }^{27} \mathrm{Al}$ signal is directly proportional to the number of aluminum atoms in the sample. An accurate determination of the total aluminum content may then be obtained by comparing integrated signal intensities within a spectrum or between spectra. 
A notable finding of this study is that the aluminum in the Fe-doped samples can be divided into groups that are distinguishable on the basis of their response to excitation pulses of differing lengths. From the linewidths and Fe-dependence of the spectra, it can be surmised that one group consists of aluminum nuclei in a relatively Fe-free environment, and the other group consists of aluminum nuclei with iron nuclei in closer proximity. The spectra shown on the left side of Figure 3.2 represent Al in close proximity to $\mathrm{Fe}$ in the samples. These signals were observed at a pulse length of $12.0 \mu \mathrm{s}$. Application of a shorter pulse length $(1.1 \mu \mathrm{s})$ reveals spectra that can be attributed to Al that is not closely associated with Fe (right side of Figure 3.2). In both cases, the observability of the ${ }^{27} \mathrm{Al}$ NMR signal implies that Fe and $\mathrm{Al}$ are not randomly mixed, but that some segregation, or ordering, of the metals occurs.

Considerable effort would be required to definitively determine the origin of the pulse-width response. However, it can be hypothesized that it is due to "tilting" of the effective magnetic field experienced by the ${ }^{27} \mathrm{Al}$ nuclei. It is well-known that paramagnetic centers in solids, acting as powerful little magnets, can tilt the magnetic field other nuclei experience in their vicinity, in addition to shifting their resonance frequencies. In other words, the ${ }^{27} \mathrm{Al}$ nuclei would not be aligned in the direction of the field produced by the superconducting magnet, but along an axis determined by the local distribution of Fe nuclei. If this happened, then the radiofrequency coil would not be perpendicular to the ${ }^{27} \mathrm{Al}$ magnetization, and the radiofrequency pulses would be attenuated, resulting in less efficient excitation of the ${ }^{27} \mathrm{Al}$ resonance. Longer pulses would then be needed for maximal signal of ${ }^{27} \mathrm{Al}$ nuclei close to $\mathrm{Fe}$.

In summary, these results demonstrate the potential of ${ }^{27} \mathrm{Al}$ NMR spectroscopy for identifying and quantifying the environments occupied by aluminum atoms in mixed phase, non-crystalline solid oxides. Aluminum atoms in fourfold and sixfold coordinate sites can be separately observed in NMR spectra, and even when different species with aluminum atoms in sixfold sites are simultaneously present, e.g., boehmite and gibbsite, there are differences in spectral features that still make it possible to discriminate between the two.

\subsection{Sodium-23 NMR Spectroscopy of Sludge Simulants and Salts}

The gyromagnetic ratio and isotopic abundance of the ${ }^{23} \mathrm{Na}$ nuclide are similar to ${ }^{27} \mathrm{Al}$. For NMR measurements, the most significant differences between ${ }^{23} \mathrm{Na}$ and ${ }^{27} \mathrm{Al}$ are in the electronic environments of the nuclei, as manifested in the magnitudes and distributions of typical quadrupolar coupling constants. Figure 3.3 displays representative ${ }^{23} \mathrm{Na}$ MAS NMR spectra. For the same sample masses and experiment times, ${ }^{23} \mathrm{Na}$ results roughly equivalent to ${ }^{27} \mathrm{Al}$ spectra in sensitivity and information content are obtained.

The higher signal-to-noise ratio of the $\mathrm{Na}_{7} \mathrm{~F}\left(\mathrm{PO}_{4}\right)_{2} \bullet 19 \mathrm{H}_{2} \mathrm{O}$ spectrum compared to the $\mathrm{S}-101$ simulant is mainly attributable to two factors: the higher concentration of $\mathrm{Na}$ in the salt $(22.6 \mathrm{wt} \% \mathrm{vs}$. approximately $1.5 \mathrm{wt} \%$ ) and the narrower linewidth of its resonance. The latter factor is due to the high crystallinity of the sample, which implies a smaller distribution of possible environments for sodium as compared to the amorphous tank simulant. This observation suggests that the precipitation of $\mathrm{Na}_{7} \mathrm{~F}\left(\mathrm{PO}_{4}\right)_{2} \bullet 19 \mathrm{H}_{2} \mathrm{O}$ in sludge or other tank-waste material should be readily determined from the characteristic position and width of its ${ }^{23} \mathrm{Na}$ resonance. 

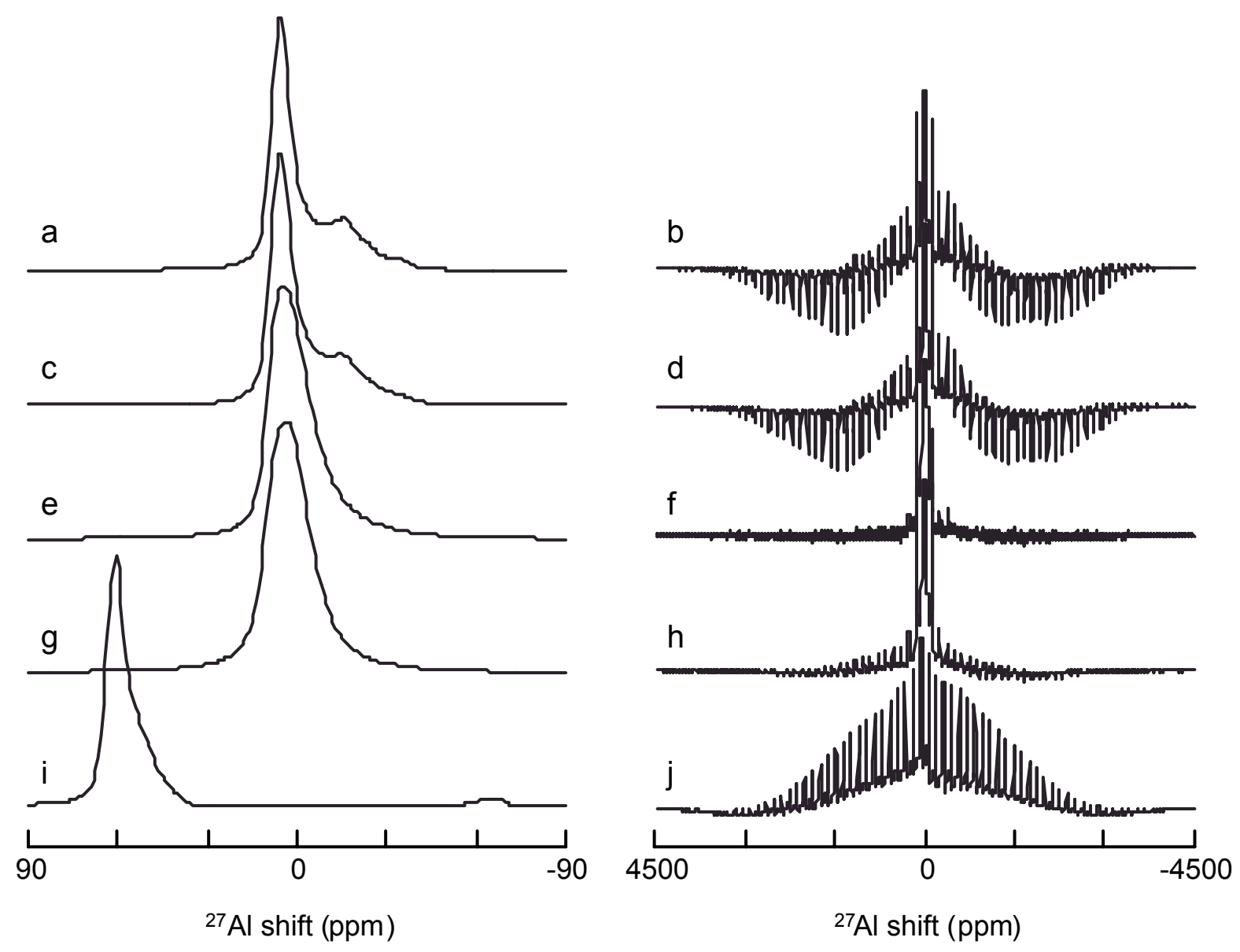

Figure 3.1. Proton-Decoupled MAS NMR Echo Spectra of S-23 Gibbsite (a, b), S-11 Gibbsite (c, d), HiQ-10 Boehmite (e, f), Tank S-101 Sludge Simulant (prepared by Lynntech, Inc.) (g, h), and A-400 Nepheline (i,j). The sample spinning speed was $10 \mathrm{kHz}$, and a $0.5 \mathrm{~ms}$ refocusing delay was used in the two-pulse echo. In the spectra on the left, only the line corresponding to the central ${ }^{27} \mathrm{Al}$ resonance is shown; on the right, the entire MAS sideband patterns are displayed. The spectra on the right were expanded vertically, and the intense centerband signal was truncated for easier viewing. The two gibbsite samples differ in average particle size. 

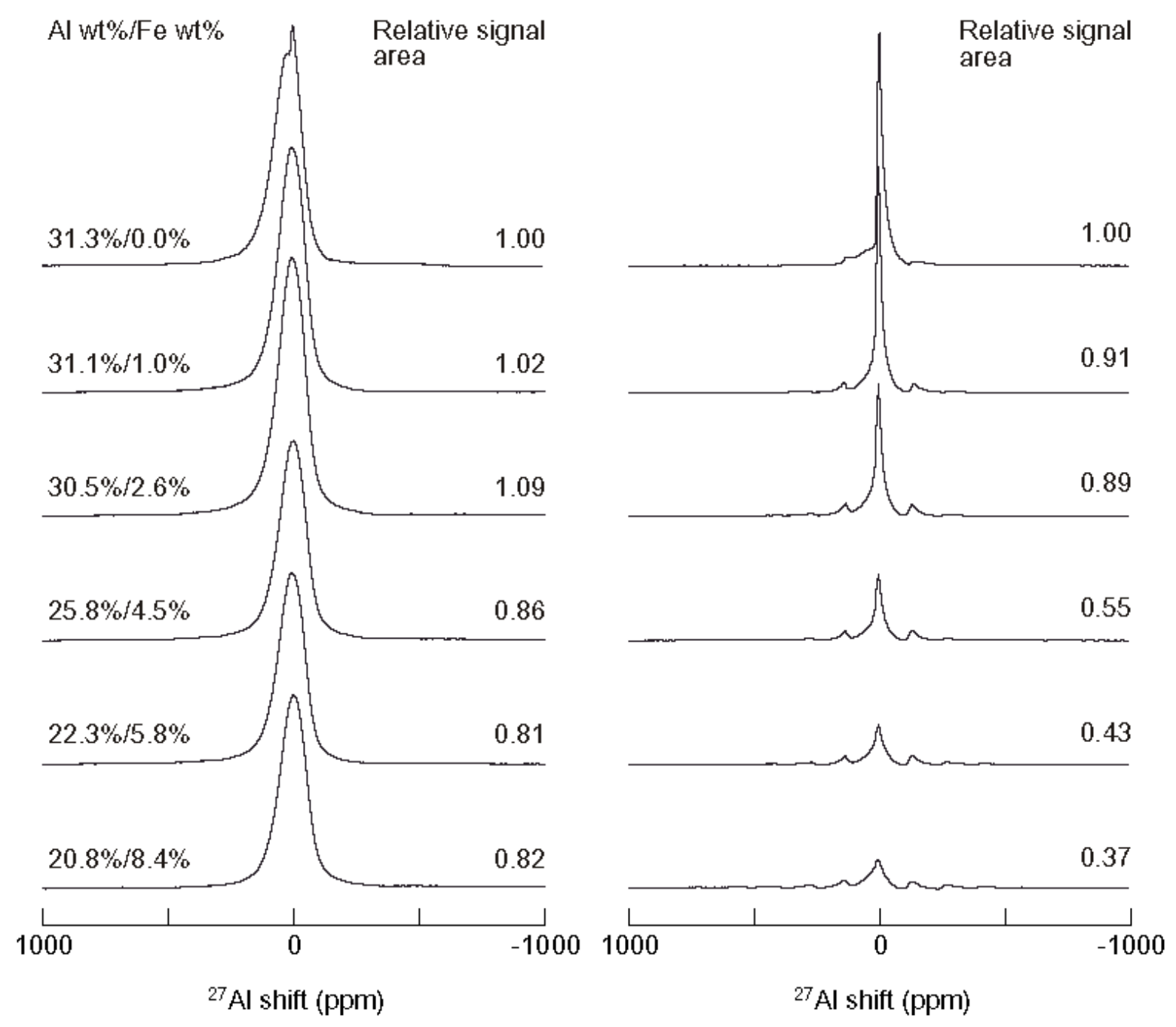

Figure 3.2. Proton-Decoupled MAS NMR Spectra of Aluminates with Varying Iron Concentrations. The time-domain signals were acquired following a single-excitation pulse of duration $12.0 \mu \mathrm{s}$ (left series) or $1.1 \mu$ s (right series). The sample spinning speed was $10 \mathrm{kHz}$. The areas and vertical scales of spectra on each side have been normalized according to the masses of the samples. The spectra are averages of 256 scans, for a total acquisition time of $21 \mathrm{~min}$. 


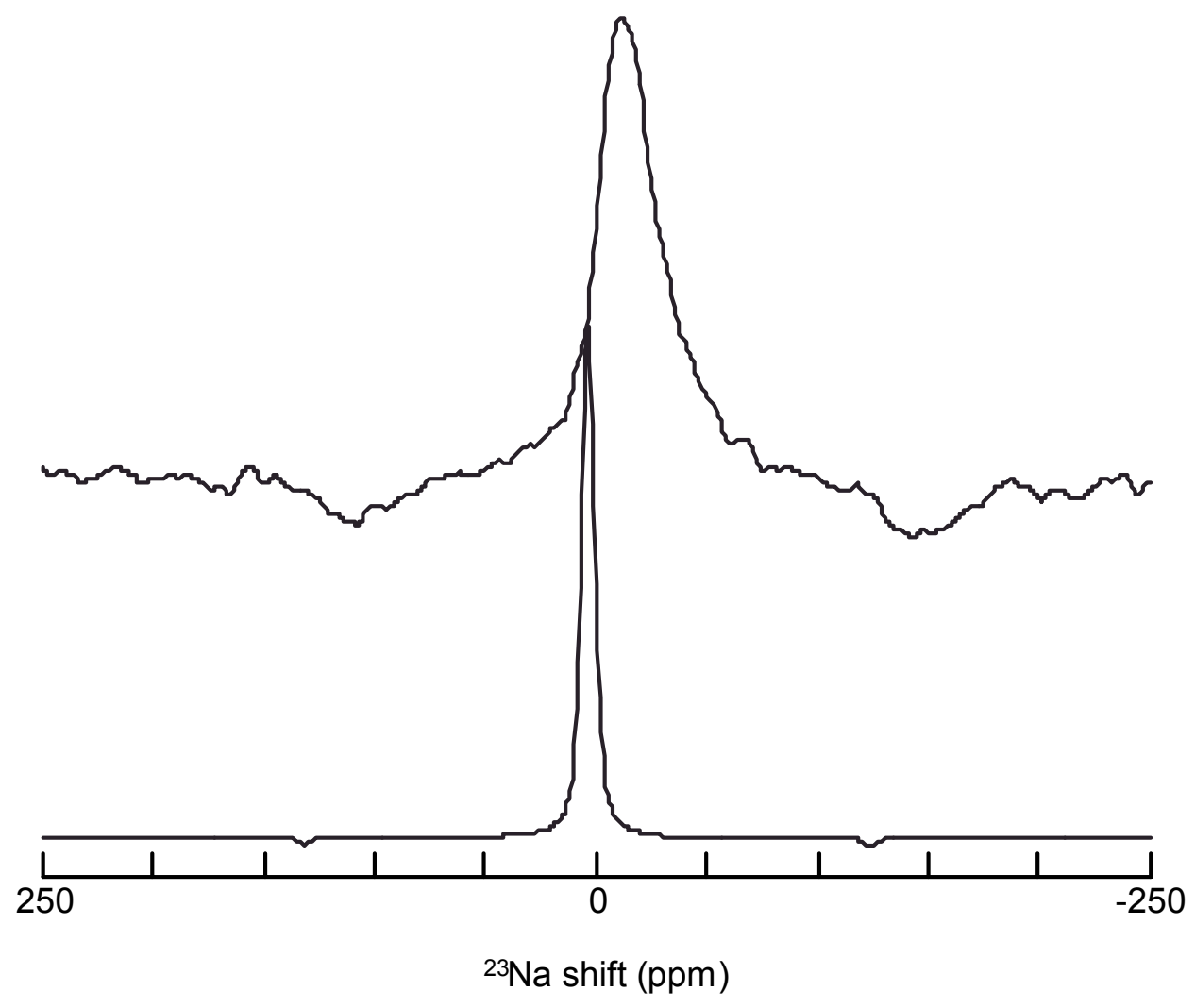

Figure 3.3. Proton-Decoupled ${ }^{23} \mathrm{Na}$ MAS NMR Echo Spectra of Tank S-101 Sludge Simulant (top) and $\mathrm{Na}_{7} \mathrm{~F}\left(\mathrm{PO}_{4}\right)_{2} \bullet 19 \mathrm{H}_{2} \mathrm{O}$ (bottom). The sample spinning speed was $10 \mathrm{kHz}$, and a $0.25 \mathrm{~ms}$ refocusing delay was used in the two-pulse echo.

\subsection{Conclusions and Recommendations}

This work demonstrates the potential utility in applying MAS solid-state NMR spectroscopy to the study of Hanford tank sludge solids. We have shown that ${ }^{27}$ Al NMR signals can be easily observed in materials containing Fe(III) in concentrations that could be expected to be present in Hanford tank sludge solids. Different Al-containing species can be distinguished by varying the pulse length-Al associated with Fe being observed at longer pulse lengths, while Al not associated with Fe being evident at shorter pulse lengths. This work has also indicates ${ }^{23} \mathrm{Na}$ NMR can likely be used to identify specific Nacontaining phases present in tank wastes. It can be expected that other NMR-active nuclides can be examined to yield information about specific phases present in tank-waste solids.

Recommendations for future work include:

- Developing the methodology required to quantify specific species present in tank solids

- Examining actual tank waste by MAS solid-state NMR spectroscopy

- Measuring spectra for other important nuclides, specifically ${ }^{19} \mathrm{~F},{ }^{29} \mathrm{Si}$, and ${ }^{31} \mathrm{P}$. 



\subsection{References}

Akitt, J. W. 1987. “Aluminum, Gallium, Indium, and Thallium.” In: Multinuclear NMR, J. Mason, ed. Plenum, New York.

Barton, W. B., G. T. MacLean, C. D. Meng, and C. M. Winkler. 1995. Status and Progress in Sludge Washing: A Pivotal Pretreatment Method, WHC-SA-2696-FP, Westinghouse Hanford Company, Richland, Washington.

Grant, D. M. and R. K. Harris, eds. 1996. Encyclopedia of Nuclear Magnetic Resonance, Wiley, West Sussex, England.

Henshaw, J., N. Pilkington, and P. Cake. 1998. Kinetics of Sludge Dissolution: Dissolution Rates of Gibbsite Prgress Report, AEAT-4277, AEA Technology, Oxon, United Kingdom.

Laszlo, P. 1983. "The Alkali Metals.” In: The Multinuclear Approach to NMR Spectroscopy, J. B. Lambert and F. G. Riddell, eds. Reidel, Dordrecht, Holland.

Lumetta, G. J., and B. M. Rapko. 1994. Washing and Alkaline Leaching of Hanford Tank Sludges: A Status Report, PNL-10078, Pacific Northwest National Laboratory, Richland, Washington.

Lumetta, G. J., B. M. Rapko, M. J. Wagner, J. Liu, and Y. L. Chen. 1996a. Washing and Caustic Leaching of Hanford Tank Sludges: Results of FY 1996 Studies, PNNL-11278, Rev. 1, Pacific Northwest National Laboratory, Richland, Washington.

Lumetta, G. J., M. J. Wagner, F. V. Hoopes, and R. T. Steele. 1996b. Washing and Caustic Leaching of Hanford Tank C-106 Sludge, PNNL-11381, Pacific Northwest National Laboratory, Richland, Washington.

Lumetta, G. J., I. E. Burgeson, M. J. Wagner, J. Liu, and Y. L. Chen. 1997. Washing and Caustic Leaching of Hanford Tank Sludges: Results of FY 1997 Studies, PNNL-11636, Pacific Northwest National Laboratory, Richland, Washington.

Lumetta, G. J., B. M. Rapko, J. Liu, D. J. Temer, and R. D. Hunt. 1998. Washing and Caustic Leaching of Hanford Tank Sludges: Results of FY 1998 Studies, PNNL-12026, Pacific Northwest National Laboratory, Richland, Washington.

Lumetta, G. J., K. J. Carson, L. P. Darnell, L. R. Greenwood, F. V. Hoopes, R. L. Sell, S. I. Sinkov, C. Z. Soderquist, M. W. Urie, J. J. Wagner. 2001. Caustic Leaching of Hanford Tank S-110 Sludge, PNNL-13702, Pacific Northwest National Laboratory, Richland, Washington.

MacLean, G. T. 1997. Computer Simulation of the Leaching and Washing of Waste in Tanks C-106, AY102, $A Z-101$, and AZ-102, HNF-SD-TWR-PE-001, SGN Eurisys Services Corporation, Richland, Washington. 
Meng, C. D., G. T. MacLean, and B. C. Landeene. 1994. Computer Simulation of Laboratory Leaching and Washing of Tank Waste Sludges, WHC-SD-WM-ES-312, Westinghouse Hanford Company, Richland, Washington.

Morgan, M., and J. Henshaw. 1999. Kinetics of Sludge Dissolution: Dissolution Rates of Gibbsite Prgress Report (2), AEAT-5440, AEA Technology, Oxon, United Kingdom.

Rai, D., M. Sass, and D. A. Moore. 1987. "Chromium(III) Hydrolysis Constants and Solubility of Chromium(III) Hydroxide.” Inorg. Chem., 26: 345-349.

Rapko, B. M, G. J. Lumetta, and M. J. Wagner. 1995. Washing and Caustic Leaching of Hanford Tank Sludges: Results of FY 1995 Studies, PNL-10712, Pacific Northwest Laboratory, Richland, Washington.

Slade, R. C. T., J. C. Southern, and I. M. Thompson. 1991a. “27 Al Nuclear Magnetic Resonance Spectroscopy Investigation of Thermal Transformation Sequences of Alumina Hydrates. 1. Gibbsite, $\gamma$ $\mathrm{Al}(\mathrm{OH})_{3} . "$ J. Mater. Chem, 1: 563-568.

Slade, R. C. T., J. C. Southern, and I. M. Thompson. 1991b. “27 Al Nuclear Magnetic Resonance Spectroscopy Investigation of Thermal Transformation Sequences of Alumina Hydrates. 2. Boehmite, $\gamma-$ AlOOH.” J. Mater. Chem, 1: 875-879.

Temer, D. J., and R. Villarreal. 1995. Sludge Washing and Alkaline Leaching Tests on Actual Hanford Tank Sludge: A Status Report, LAUR-95-2070, Los Alamos National Laboratory, Los Alamos, New Mexico.

Temer, D. J., and R. Villarreal. 1996. Sludge Washing and Alkaline Leaching Tests on Actual Hanford Tank Sludge: FY 1996 Results, LAUR-96-2839, Los Alamos National Laboratory, Los Alamos, New Mexico.

Temer, D. J., and R. Villerreal. 1997. Sludge Washing and Alkaline Leaching Tests on Actual Hanford Tank Sludge: FY 1997 Results, LAUR-97-2889, Los Alamos National Laboratory, Los Alamos, New Mexico.

Toghiani, R. K., J. S. Lindner, C. Barfield, and E. C. Beahm. 1998. Saltcake Dissolution Modeling, FY 1998 Status Report, DIAL-40395-TR98-1.2, Mississippi State University, Starkville, Mississippi.

Toghiani, R. K., J. S. Lindner, C. F. Weber, and R. D. Hunt. 2000. Modeling of Sulfate Double-salt in Nuclear Wastes. ORNL/TM-2000/317, Oak Ridge National Laboratory, Oak Ridge, TN.

U.S. Department of Energy/Office or River Protection (DOE/ORP). 2001. River Protection Project Project Management Plan, DOE/ORP-2000-06, Richland, Washington.

http://www.hanford.gov/orp/documents/orp-2000-06/index.html\#P572_20332

Weber, E. J. 1982. Aluminum Hydroxide Dissolution in Synthetic Sludges, DP-1617, Savannah River Laboratory, Aiken, South Carolina.

Woessner, D. E. 1989. "Characterization of clay minerals by ${ }^{27} \mathrm{Al}$ nuclear magnetic resonance spectroscopy.” Am. Mineralogist, 74: 203-215. 


\section{Distribution}

No. of

Copies

OFFSITE

Harry Babad

2540 Cordova $\mathrm{Ct}$.

Richland, Washington 99352

Kurt Gerdes

U.S. Department of Energy

Office of Technology Systems

EM-53 Cloverleaf 1186

U.S. Department of Energy

PO Box 23865

Germantown, Maryland 20026-3865

David Hobbs

Westinghouse Savannah River Co.

773-A

Aiken, South Carolina 29808

Phil McGinnis

Oak Ridge National Laboratory

P.O. Box 2008

Oak Ridge, Tennessee 37831-6223

John Swanson

1318 Cottonwood

Richland, Washington
No. of

Copies

OFFSITE

Major Thompson

Westinghouse Savannah River Co.

773-A, C140

Aiken, South Carolina 29808

\section{ONSITE}

7 DOE Richland Operations Office

J. Cruz

H6-60

M.J. Glasper

K8-50

B.M. Mauss

H6-60

T.P. Pietrok

K8-50

3 Bechtel

R. Peterson H4-02

P. Townson H4-02

T. Wright H4-02

$2 \quad \mathrm{CHG}$

K.A. Gasper L4-07

D.J. Washenfelder R2-12

1 Fluor Hanford Corporation

D.L. Herting T6-07 
No. of

Copies

\section{ONSITE}

37 Pacific Northwest National Laboratory

TFA Technical Team Office (8) K9-69

W.F. Bonner K9-14

H.M. Cho (10) K8-98

W.C. Cosby K7-62

J.G.H. Geeting P7-28

G.R. Golcar K6-24

D.E. Kurath P7-28

G.J. Lumetta (10) P7-22

B.M. Rapko P7-25

Technical Report Files (2) 